\title{
CONDIÇÕES DE ARMAZENAMENTO E SUA INFLUÊNCIA NA INCIDÊNCIA DE INSETOS EM SEMENTES DE SORGO
}

\author{
F. LOPES FILHO' ${ }^{1}$, MARCOS VINICIUS ASSUNÇÃO \\ E FRANCISCO VALTER VIEIRA ${ }^{3}$
}

RESUMO. O objetivo deste trabalho foi avaliar a influência do tipo de embalagem, da umidade relativa e da temperatura de armazenamento na incidência de insetos em sementes de sorgo granífero, cv. EA-955. As sementes foram acondicionadas em latas de metal vedadas, sacos de pano (algodão) e sacos de polipropileno e armazenamento sob condições naturais, em quatro locais do Estado do Ceará: Fortaleza, Quixadá, Morada Nova e Ubajara. No início, e a cada dois meses durante o período de armazenamento, determinou-se a flutuação do conteúdo de umidade das sementes e a porcentagem de sementes danificadas por insetos. Foi usado o delineamento de blocos inteiramente casualizados, com tratamentos constituídos de cinco períodos de armazenamento, $(0,2,4$, 6 e 8 meses), três tipos de embalagem (lata, pano e polipropileno), com quatro repetições. Observou-se que a lata de metal é a embalagem que melhor preserva as sementes contra o ataque dos insetos. Os insetos-pragas constatados a depreciarem as sementes são: a traça-dos-cereais, Sitotroga cerealella (Oliv. 1789) (Lepidoptera, Gelechiidae), o besouro, Tribolium castaneum (Herbst, 1797) (Coleoptera, Tenebrionidae) e o gorgulho-do-milho, Sitophilus zeamais (Mots., 1855) (Coleoptera, Curculionidae). As sementes armazenadas em Ubajara foram menos danificadas que as sementes armazenadas nas outras localidades.

Termos para indexação: período de armazenamento, ataque de insetos, umidade, Sorghum bicolor (L.) Moench.

\section{STORAGE CONDITIONS AND THEIR EFFECTS ON INSECTS INCIDENCE IN SORGHUM SEEDS}

ABSTRACT. The objective of this research was to evaluate the package type, moisture content and the storage temperature effects on insect incidence in grain sorghum seeds. The seeds were packed in sealed cans, cloth and polypropylene bags, and stored under natural conditions in four sites in the state of Ceará: Fortaleza, Quixada, Morada Nova and Ubajara. In the research beginning and every two months, during the storage

1 Engo Agrō, M.Sc., EMBRAPA/Centro de Pesquisa Agropecuária do Trópico Semi-Árido (CPATSA). Caixa Postal, 23. CEP 56300, Petroiina, PE.

2 Engo Agroo, Ph.D, do Centro de Ciências Agrárias da Universidade Federal do Ceará. Caixa Postal, 1257. CEP 60000, Fortaleza, CE.

3 Eng ${ }^{\circ}$ Agro ${ }^{\circ}$, Doutor, Prof. do Centro de Ciências Agrárias da Universidade Federal do Ceará. 
period the seed moisture content flutuation and the insects damaged seeds percentage were checked. The experimental designe was totaly randomized and consist of five storage periods, $(0,2,4,6$ and 8 months), three package types (sealed cans, cloth and polypropylene) and four replications. It was observed that metal can is the best in preserving the seeds against insect damage. According to the obtained data, the insects that damaged the seeds are: the angoumois grain month, Sitotroga cerealella (Oliv. 1789), the red flour bettle Tribolium castaneum (Herbst, 1797) and the corn weevil, Sitophilus zeamais (Mots., 1855). It was found that the seeds stored in Ubajara were less damaged than the seeds stored in other places.

Index terms: storage period, insects damage, moisture, Sorghum bicolor (L.) Moench.

\section{INTRODUÇÃO}

A qualidade final da semente $e$ influenciada por numerosos fatores, tais como: tipo de embalagem, condições de armazenamento em relação à temperatura e à umidade relativa. Destes, os dois últimos são os fatores que mais comprometem a manutenção da qualidade sanitária da semente, durante o armazenamento. A propósito disso, Cotton (1954), citado por Popinigis (1977), mostra os efeitos da temperatura de armazenamento e do teor de umidade de sementes de trigo, no aumento da população de Sitophilus ory$z a e$, após um período de cinco meses de armazenamento. O autor constatou que quanto maior o teor de umidade da semente, maior o desenvolvimento da população de insetos.

Harrington (1972) afirma que os problemas de manutenção da germinação crescem com o conteúdo de umidade da semente. Isto pode ser generalizado como segue:

a) Umidade de semente acima de 18 a $20 \%$ - pode ocorrer aquecimento;

b) Umidade da semente acima de 8 a $9 \%$ - os insetos tornam-se ativos e se reproduzem.

Segundo Hartman \& Kerster (1975), as mais importantes condições para se obter uma boa conservação de sementes são o teor apropriado de umidade da semente e a baixa temperatura de armazenamento. Destas condições, a relação umidade-temperatura tem a maior importância prática.

Para Agrawal (1976), a viabilidade da semente armazenada pode ser afetada por numerosos fatores isolados, mas que interagem entre si, tais como: umidade da semente, temperatura de armazenamento, trocas gasosas, condições físicas das sementes, estágio de maturação, vigor e germinação inicial e infestação de insetos. Menciona ainda que, de todos, os mais influentes são a umidade da semente e a temperatura de armazenamento. Por sua vez, Popinigis (1977) menciona que, no decorrer do armazenamento, um acréscimo na temperatura promove aceleração das atividades respiratórias, além de favorecer a ação de insetos e fungos, resultando, desse modo, numa rápida deterioração da semente.

Revista Brasileira de Sementes - Ano 9-no 3 - Brasília-DF - 1987 
Paricha et al. (1977) arrazoaram que sementes de arroz são higroscópicas e que seu teor de umidade sofre oscilaçâo com a umidade relativa do ambiente. Do mesmo modo, a deterioração da semente aumenta progressivamente com o incremento da umidade relativa e com o prolongamento do tempo de armazenamento.

Segundo Toledo \& Marcos Filho (1977), os maiores prejuízos causados pelos insetos às sementes, de um modo geral, ocorrem durante o período de armazenamento, podendo ocasionar deterioração parcial ou total das mesmas e que a ocorrência das infestações variam dependendo das condições do ambiente. Afirmam, ainda, que os insetos-pragas de sementes estocadas mostram ótimo desempenho em temperaturas de $23^{\circ} \mathrm{C}$ a $35^{\circ} \mathrm{C}$ e que o teor de umidade da semente que favorece o desenvolvimento de insetos é, aproximadamente, $12 \%$ a $15 \%$. Carvalho \& Nakagawa (1983) também afirmam que a temperatura na faixa de $23^{\circ} \mathrm{C}$ a $35^{\circ} \mathrm{C}$ e a umidade da semente variando de $12 \%$ a $15 \%$ favorecem o desenvolvimento dos insetos.

Um outro fator que tem grande influência na manutenção da qualidade da semente é o tipo de embalagem utilizada. Quando são armazenadas em embalagens por meio das quais se processa a troca de vapor d'água com a atmosfera, as sementes tendem a perder ou a ganhar umidade, dependendo da temperatura e da umidade relativa do meio ambiente.

Nos Estados Unidos da América, Coleman \& Peel (1952), ao armazenarem sementes de beterraba, alface, cenoura e pepino em latas de metal, sacos de pano e de papel, em ambientes secos, úmidos e frios, concluíram que a lata de metal proporcionou melhor conservação das sementes em meio a todas essas condições estudadas. Resultados parecidos foram obtidos por Pimentel et al. (1978) e Figueiredo et al. (1980), em condições tropicais e subtropicais brasileiras.

Harrington (1963), citado por Toledo \& Marcos Filho (1977), ao estudar os efeitos da embalagem e das condições do ambiente, acondicionou sementes de cebola em sacos de papel + asfalto, papel + polietileno, papel + alumínio e sacos de pano, contendo $11 \%$ de umidade e armazenou-as sob a ação de altas temperaturas e altas umidades relativas. Ao final de 18 meses de armazenamento, observou-se: a) a alta temperatura e a alta umidade relativa prejudicaram a conservação da semente em embalagens permeáveis; b) a alta umidade das sementes e a temperatura elevada favoreceram a deterioração, mesmo em embalagem hermética. $O$ autor constatou ainda que, de um modo geral, recipientes a prova de troca de umidade são prejudiciais se as sementes forem armazenadas com teor inadequado de umidade, pois, desenvolvem a respiração anaeróbica e, deste modo, ocorre a liberação de substâncias tóxicas que começam a prejudicá-las intensamente.

Popinigis (1977) afirmou que, ao se acondicionarem sementes em embalagens permeáveis à umidade, ocorrem oscilaçōes no teor de umidade, conforme as variações da umidade relativa do ar e que, se o local apresenta alta umidade relativa, proporcionará um incremento no conteúdo de umidade das sementes, provocando, conseqüentemente, aceleração nos processos de- 
teriorantes e rápida perda de sua qualidade.

Segundo Oliveira (1981), a embalagem tipo lata preserva melhor a qualidade de sementes de feijão-de-corda do que sacos de pano e de papel, quando armazenadas em ambiente com temperatura e umidade relativa variando nas faixas de $27^{\circ} \mathrm{C} \pm 6^{\circ} \mathrm{C}$ e $80^{\circ} \pm 7 \%$, respectivamente. Por outro lado, Pelegrini (1982) constatou que, de modo geral, altos teores de umidade relativa favorecem o aumento da temperatura da semente, provocado pela aceleração de sua respiração, proporcionam maior susceptibilidade da semente a injúrias térmicas no decorrer da secagem e permitem uma atividade maior de insetos.

Este trabalho objetiva avaliar os efeitos do tipo de embalagem, umidade relativa e temperatura no ataque de insetos em sementes de sorgo armazenadas em diferentes locais do Estado do Ceará.

\section{MATERIAL E MÉTODOS}

Sementes de sorgo granífero, cv. EA-955, foram acondicionadas em três tipos de embalagens diferentes: latas de metal vedadas, sacos de pano (algodão) e sacos de polipropileno, com capacidade individual para 400 gramas.

Ao acondicionamento das sementes nas respectivas embalagens, seguiu-se o seu armazenamento por um período de oito meses, sob condições normais de ambiente, em quatro locais do Estado do Ceará: Fortaleza, Quixadá, Morada Nova e Ubajara, cujos dados da temperatura e umidade relativa encontram-se na Tabela 1.

No final de cada um dos períodos de armazenamento, as sementes foram transportadas para o laboratório de Tecnologia de Sementes do Centro de Ciências Agrárias da Universidade Federal do Ceará, em Fortaleza, onde avaliaram-se: teor de umidade das sementes e porcentagem de sementes danificadas por insetos. Para determinar o teor de umidade das sementes, foram tomadas duas repetições de $50 \mathrm{~g}$ de cada tratamento e, em seguida, colocadas em estufa elétrica à temperatura de $105^{\circ} \mathrm{C}$, durante 24 horas. Os resultados expressos em porcentagem foram calculados por diferença de peso, com base no peso úmido das sementes (Brasil 1976). A porcentagem de sementes danificadas foi avaliada, retirando-se, aleatoriamente, de cada tratamento, quatro repetições de 100 sementes. As sementes foram contadas uma a uma, com o auxílio de uma lupa, e colocadas para germinar. O resultado obtido foi expresso em porcentagem.

Os insetos causadores dos danos às sementes armazenadas foram identificados e classificados pelo Setor de Entomologia do Departamento de Fitotecnia do Centro de Ciências Agrárias da Universidade Federal do Ceará, segundo Gallo et al. (1978).

Os tratamentos utilizados - cinco períodos de armazenamento $(0,2,4$, 6 e 8 meses) e três tipos de embalagens (lata, pano e polipropileno) - em arranjo fatorial 5 × 3 foram dispostos em delineamento inteiramente casualizados, com quatro repetições. 
TABELA 1. Valores mensais das temperaturas máxima, média, mínima e umidade relativa dos locais em que as sementes foram armazenadas, 1982.

\begin{tabular}{|c|c|c|c|c|c|c|c|c|c|c|c|c|c|c|c|c|}
\hline \multirow{3}{*}{$\begin{array}{l}\text { Armazenamento } \\
\text { (mês) }\end{array}$} & \multicolumn{3}{|c|}{ Fortaleza } & \multirow{3}{*}{$\begin{array}{l}\text { U.R. } \\
(\%)\end{array}$} & \multicolumn{3}{|c|}{ Quixadá } & \multirow{3}{*}{$\begin{array}{l}\text { U.R. } \\
\text { (\%) }\end{array}$} & \multirow{2}{*}{\multicolumn{3}{|c|}{$\begin{array}{l}\text { Morada Nova } \\
\text { Temperatura }\end{array}$}} & \multirow{3}{*}{$\begin{array}{l}\text { U.R. } \\
(\%)\end{array}$} & \multicolumn{3}{|c|}{ Ubajara } & \multirow{3}{*}{$\begin{array}{l}\text { U.R. } \\
\text { (\%) }\end{array}$} \\
\hline & \multicolumn{3}{|c|}{ Temperatura } & & \multicolumn{3}{|c|}{ Temperatura } & & & & & & & mperat & & \\
\hline & $\max$. & média & $\min$. & & $\max$. & média & $\min$. & & $\max$. & média & $\min$. & & $\max$. & média & $\min$. & \\
\hline 0 & 29,6 & 26,8 & 24,3 & 84,0 & 32,0 & 26,8 & 22,8 & 74,0 & 33,6 & - & - & 61,3 & 24,3 & 21,4 & 18,8 & 81,0 \\
\hline 2 & 29,9 & 26,4 & 24,0 & 81,0 & 30,3 & 25,6 & 22,0 & 73,0 & 31,3 & 27,6 & 21,8 & 63 , & 24,3 & 21,3 & 18,3 & 81,0 \\
\hline 4 & 29,5 & 26,0 & 23,0 & 76,0 & 32,4 & 25,7 & 21,2 & 71,0 & 33,0 & 28,6 & 21,0 & 54,4 & 25,7 & 21,5 & 17,4 & 75,0 \\
\hline 6 & 30,0 & 26,6 & 24,1 & 73,0 & 35,3 & 27,2 & 21,7 & 68,0 & 35,0 & 30,4 & 21,7 & 46,4 & 28,1 & 22,4 & 17,0 & 82,0 \\
\hline 8 & 30,8 & 27,5 & 25,2 & 79,0 & 35,6 & 27,7 & 22,2 & 64,0 & 35,7 & 31,0 & 22,0 & 44,6 & 28,6 & 23,2 & 18,0 & 77,0 \\
\hline Média & 29,9 & 26,5 & 23,9 & 77,8 & 33,0 & 26,5 & 21,8 & 71,2 & 33,7 & 29,4 & 21,4 & 53,3 & 26,1 & 21,9 & 17,8 & 79,1 \\
\hline
\end{tabular}

Fonte: Ceará. Universidade Federal 1982. 
A análise estatística foi realizada isoladamente para cada local. Os dados de porcentagem de sementes danificadas por insetos, foram transformados em Arc.sen $\sqrt{\%}$, de acordo com Snedecor \& Cochrane (1980).

\section{RESULTADOS E DISCUSSÃO}

\section{Umidade das sementes}

$\mathrm{O}$ teor médio de umidade das sementes de sorgo, armazenadas nos quatro locais, encontra-se na Tabela 2. Constata-se que as referidas sementes sofreram oscilações no conteúdo de umidade durante todo o período de armazenamento. Observaram-se, no entanto, maiores oscilações, naquelas sementes acondicionadas em sacos de pano e de polipropileno (exceção de Morada Nova), mostrando que estas embalagens possibilitaram a permuta de umidade com o meio, além do fato de as sementes serem higroscópicas, favorecendo-lhes ganhar ou perder umidade ate que entrem em equilíbrio com o nível de umidade relativa do ambiente. Estes dados concordam com as afirmações de Popinigis (1977) e com os resultados obtidos por Paricha et al. (1977) em sementes de arroz.

TABELA 2. Umidade de sementes (\%) de sorgo, cv. EA-955, acondicionadas em diferentes tipos de embalagem e armazenadas em diferentes locais do Estado do Ceará, Brasil, 1982.

\begin{tabular}{llccccc}
\hline \multirow{2}{*}{ Local } & \multirow{2}{*}{ Embalagem } & \multicolumn{5}{c}{ Período de armazenamento (mês) } \\
\cline { 3 - 6 } & & 0 & 2 & 4 & 6 & 8 \\
\hline \multirow{3}{*}{ Fortaleza } & Lata & 13,04 & 13,24 & 12,51 & 13,97 & 13,41 \\
& Pano & 13,04 & 14,83 & 12,66 & 13,86 & 13,65 \\
& Polipropileno & 13,04 & 15,16 & 13,43 & - & - \\
Quixadá & Lata & 13,04 & 13,96 & 13,38 & 14,11 & 13,21 \\
& Pano & 13,04 & 14,83 & 13,39 & 13,14 & 12,12 \\
& Polipropileno & 13,04 & 15,11 & 13,41 & 12,50 & - \\
\multirow{2}{*}{ Morada Nova } & Pata & 13,04 & 12,79 & 13,55 & 13,22 & 12,38 \\
& Pano & 13,04 & 13,14 & 13,17 & - & - \\
& Polipropileno & 13,04 & 13,44 & 13,11 & - & - \\
& Lata & 13,04 & 13,06 & 12,94 & 13,58 & 14,48 \\
& Pano & 13,04 & 14,85 & 14,22 & 13,58 & 14,14 \\
& Polipropileno & 13,04 & 14,51 & 14,06 & 14,49 & 14,17 \\
\hline
\end{tabular}

Ao ser feita uma comparação entre os invólucros permeáveis (Tabela 2), constatou-se que as sementes acondicionadas nos sacos de polipropileno, notadamente até o quarto mês (exceto em Ubajara), apresentaram maior conteúdo de umidade do que aquelas acondicionadas em sacos de pano, evidenciando, provavelmente, uma maior permeabilidade do polipropileno. Esta hipótese, no entanto, precisa ser confirmada através de outras pesquisas. 
As sementes conservadas em latas, ao contrário das demais, não sofreram variações além de $1 \%$ no conteúdo de umidade, ficando, assim, fora do alcance da umidade do ambiente de armazenamento.

\section{Porcentagem de sementes danificadas por insetos}

As análises de variância da porcentagem de sementes danificadas por insetos, em função do tipo de embalagem e do período de armazenamento nos quatro locais, mostraram efeitos altamente significativos para todas as causas de variações, com exceção da interação embalagem x período, na cidade de Ubajara.

Por meio da Tabela 3, observa-se que em todos os locais, logo a partir do segundo mês de armazenamento, as sementes começaram a ser seriamente danificadas pelo gorgulho-do-milho, Sitophilus zeamais Mots., 1855 (Coleoptera, Curculionidae); traça-dos-cereais, Sitotroga cerealella (Oliv. 1789) (Lepidoptera, Gelechiidae) e pelo besouro Tribolium castaneum Herbst, 1797 (Coleoptera, Tenebrionidae).

Analisando os efeitos das embalagens destinadas à preservação das sementes (Tabela 3), verifica-se que não houve diferença significativa entre os invólucros protetores até o segundo mês de armazenamento, com exceção de Morada Nova. No entanto, a partir do quarto mês, estendendo-se ao oitavo, surgiu diferença quanto ao referido parâmetro, em todas as localidades. Nota-se, em Ubajara e Quixadá, que, apesar da ocorrência de insetos no sorgo acondicionado nas três embalagens, a porcentagem de sementes danificadas durante todo o tempo de armazenamento foi muito baixa, inclusive, em relação às sementes acondicionadas em sacos de pano, que resultaram significativamente injuriadas em Fortaleza, Quixadá e Morada Nova. Observa-se, também, que a lata de metal foi a embalagem que melhor preservou as sementes dos danos provocados pelos insetos, concordando com os dados obtidos por Coleman \& Peel (1952), Pimentel et al. (1978), Figueirêdo et al. (1980) e Oliveira (1981), utilizando, respectivamente, sementes de beterraba, milho, caupi e feijão-de-corda. Já os invólucros permeáveis (sacos de pano e polipropileno) foram os que menos conservaram as sementes, pois, por serem porosos, (polipropileno mais que o pano), facilitaram a permuta de umidade entre as sementes e o ambiente e, assim, proporcionaram condições satisfatórias de proliferação dos insetos que provocaram a sua deterioração, corroborando, deste modo, com resultados obtidos por Popinigis (1977).

Através da Tabela 3, observa-se que em todos os locais a porcentagem média de sementes danificadas pelos insetos cresceu à medida que se prolongou o tempo de armazenamento e, que até o quarto mês, os danos foram relativamente baixos. Porém, daquele mês em diante, aquelas sementes acondicionadas em sacos de polipropileno tiveram o índice de dano aumentado bruscamente, chegando a alcançar o nível de $100 \%$, aos seis meses, em Fortaleza e Morada Nova. Esta total deterioração foi influenciada pela alta umidade relativa de Fortaleza, pela elevada temperatura de Morada Nova e 
pelo conteúdo de umidade das sementes, que é considerado inadequado, principalmente, para aquelas acondicionadas em recipientes herméticos (Cotton 1954, mencionado por Popinigis 1977, Harrington 1972, Hartman \& Kerster 1975, King \& Mendonça 1964, Agrawal 1976, Popinigis 1977).

Os locais de armazenamento, através da ação dos seus fatores climáticos, tiveram marcada influência na quantidade de sementes danificadas por insetos (Tabela 3). Esta expressiva influência deveu-se aos efeitos negativos das condições ambientais (temperatura e umidade relativa elevadas), as quais, segundo Toledo \& Marcos Filho (1977) e Carvalho \& Nakagawa (1983), proporcionaram condições ideais ao desenvolvimento dos insetos, facilitando a sua reprodução e, conseqüentemente, a completa deterioração das sementes armazenadas sob tais condições. Nota-se, no entanto, que na cidade de Ubajara, ocorreu uma menor incidência de insetos no sorgo ali armazenado, por causa da temperatura, normalmente mais baixa que nas três outras cidades.

TABELA 3. Porcentagem média de sementes de sorgo granifero danificadas por insetos, em função do local, embalagem e período de armazenamento.

\begin{tabular}{|c|c|c|c|c|c|c|}
\hline \multirow{2}{*}{ Local } & \multirow{2}{*}{ Embalagem } & \multicolumn{5}{|c|}{ Perfodo de armazenamento (mês) } \\
\hline & & 0 & 2 & 4 & 6 & 8 \\
\hline Fortaleza & $\begin{array}{l}\text { Lata } \\
\text { Pano } \\
\text { Polipropileno }\end{array}$ & $\begin{array}{l}0,0 \mathrm{aA} * \\
0,0 \mathrm{aA} \\
0,0 \mathrm{aA}\end{array}$ & $\begin{array}{l}0,50 \mathrm{aAB} \\
1,50 \mathrm{aB} \\
0,75 \mathrm{aA}\end{array}$ & $\begin{array}{l}0,50 \mathrm{aAB} \\
3,25 \mathrm{bB} \\
4,75 \mathrm{bB}\end{array}$ & $\begin{array}{c}0,75 \mathrm{aAB} \\
11,25 \mathrm{bc} \\
100,00 \mathrm{cC}\end{array}$ & $\begin{array}{r}1,75 \mathrm{aB} \\
15,25 \mathrm{bC} \\
100,00 \mathrm{cC}\end{array}$ \\
\hline Quixadá & $\begin{array}{l}\text { Lata } \\
\text { Pano } \\
\text { Polipropileno }\end{array}$ & $\begin{array}{l}0,0 \mathrm{aA} \\
0,0 \mathrm{aA} \\
0,0 \mathrm{aA}\end{array}$ & $\begin{array}{l}1,25 \mathrm{aB} \\
1,00 \mathrm{aAB} \\
2,50 \mathrm{aB}\end{array}$ & $\begin{array}{l}2,25 \mathrm{aB} \\
1,75 \mathrm{aB} \\
8,50 \mathrm{bC}\end{array}$ & $\begin{array}{r}3,00 \mathrm{aB} \\
5,00 \mathrm{aC} \\
41,75 \mathrm{bD}\end{array}$ & $\begin{array}{r}4,75 \mathrm{aB} \\
12,50 \mathrm{bD} \\
100,00 \mathrm{cE}\end{array}$ \\
\hline Morada Nova & $\begin{array}{l}\text { Lata } \\
\text { Pano } \\
\text { Polipropileno }\end{array}$ & $\begin{array}{l}0,0 \mathrm{aA} \\
0,0 \mathrm{aA} \\
0,0 \mathrm{aA}\end{array}$ & $\begin{array}{l}1,25 \mathrm{aAB} \\
3,50 \mathrm{abB} \\
9,00 \mathrm{aB}\end{array}$ & $\begin{array}{r}3,75 \mathrm{aB} \\
16,00 \mathrm{bC} \\
19,00 \mathrm{bB}\end{array}$ & $\begin{array}{r}8,25 \mathrm{aB} \\
100,00 \mathrm{bD} \\
100,00 \mathrm{bC}\end{array}$ & $\begin{array}{r}12,50 \mathrm{aC} \\
100,00 \mathrm{bD} \\
100,00 \mathrm{bC}\end{array}$ \\
\hline Ubajara & $\begin{array}{l}\text { Lata } \\
\text { Pano } \\
\text { Polipropileno }\end{array}$ & $\begin{array}{l}0,0 \mathrm{aA} \\
0,0 \mathrm{aA} \\
0,0 \mathrm{aA}\end{array}$ & $\begin{array}{l}1,00 \mathrm{aA} \\
1,75 \mathrm{aB} \\
1,25 \mathrm{aA}\end{array}$ & $\begin{array}{l}6,75 \mathrm{abB} \\
3,25 \mathrm{aB} \\
8,25 \mathrm{bB}\end{array}$ & $\begin{array}{c}7,00 \mathrm{aB} \\
5,75 \mathrm{aBC} \\
11,00 \mathrm{aB}\end{array}$ & $\begin{array}{c}8,50 \mathrm{abB} \\
7,25 \mathrm{aC} \\
14,25 \mathrm{bB}\end{array}$ \\
\hline
\end{tabular}

* Médias seguidas pela mesma letra não diferem estatisticamente (TUKEY 5\%), letras minúsculas para comparação na vertical e maiúsculas para comparação na horizontal.

Após a discussão dos parâmetros acima, fica evidenciado que a embalagem, tipo lata, proporcionou uma maior proteção das sementes contra o ataque dos insetos. Entre as embalagens porosas, os resultados mostram ser o polipropileno menos indicado do que o pano para conservação das sementes de sorgo, por ser aquele mais poroso do que este. Vale salientar, no entanto, que em virtude da existência de diferentes tipos de pano e polipropileno, sugere-se a realização de outros trabalhos, com a finalidade de comparar os mais variados e possíveis tipos de invólucros porosos destinados à preservação das sementes armazenadas contra o ataque dos insetos.

Considerando-se os diversos Iocais, Ubajara parece ser o mais indicado para o armazenamento, em virtude de sua baixa temperatura, apesar da ele- 
vada umidade relativa do ar. Antes, porém, o teor de umidade das sementes deve ser ajustado, pois, sabe-se que existe um teor máximo de umidade considerado seguro para a conservação de cada espécie de semente. Sementes nestas condições teriam a respiração diminuida e, conseqüentemente, conservar-se-iam viáveis por um período maior.

\section{CONCLUSÕES}

1. A embalagem hermética (lata) é a que melhor preserva as sementes contra o ataque de insetos.

2. Os insetos-pragas constatados a depreciarem a semente de sorgo são: o gorgulho-do-milho, Sitophilus zeamais Mots., 1855 (Coleoptera, Curculionidae), o besouro, Tribolium castaneum Herbst., 1797 (Coleoptera, Tenebrionidae) e a traça-dos-cereais, Sitotroga cerealella (Oliv. 1789) (Lepidoptera, Gelechiidae).

3. Dentre as embalagens permeáveis testadas, o polipropileno é o menos indicado para preservar a semente de sorgo contra os danos dos insetos, por ser mais poroso do que o pano.

\section{REFERÊNCIAS}

AGRAWAL, P.K. Identification of suitable seed places in Indian on the basis of temperature and relative humidity conditions. Seed Research, 4(1):6-22, 1976.

BRASIL. Ministério da Agricultura. DNPV. Divisão de Sementes e Mudas. Regras para Análise de Sementes. Brasília, 1976. 188p.

CARVAlHO, N.M. de \& NAKAGAWA, J. Sementes: Ciência, Tecnologia e Produção. 2. ed. rev. Campinas, Fundação Cargill, 1983. 429p.

CEARÁ, UNIVERSIDADE FEDERAL. Centro de Ciências Agrárias, Fortaleza, CE. Boletim Agrometeorológico. Fortaleza, CE. 1982. 40p.

COLEMAN, F.B. \& PEEL, A.C. Storage of seed. Queensland Agron J., 74:265-76, 1952.

FIGUEIREDO, F.J.C.; CARVALHO, J.E.U.; FRAZÃO, D.A.C. Conservação de sementes de caupi em diferentes tipos de acondicionadores e seus efeitos na qualidade fisiológica durante o armazenamento. In: Empresa Brasileira de Pesquisa Agropecuária, CPATU, Belém, PA. Relatório Técnico Anual do Centro de Pesq. Agrop. Trop. Úmido - 1979. Belém, 1980. p.78-9. 
GALLO, D.; NAKANO, O.; SILVEIRA NETO, S.; CARVALHO, R.P.L.; BATISTA, G.C.; BERTI FILHO, E.; PERRA, J.R.P.; ZUCCHI, R.A. \& ALVES, S.B. Manual de Entomologia Agrícola. São Paulo, Editora Agronômica CERES, 1978. 531p.

HARRINGTON, J.F. Seed storage and longevity. In: Koslowski, T.T.; ed. Seed biology. New York, Academic, 1972. Vol. 3. p.145-245.

HARTMAN, H.T. \& KERSTER, D.E. Plant propagation; Principles and Practices. 3 ed. Englewood Cliffs, New Jersey, Prentice Hall. 1975. $662 \mathrm{p}$.

KING, E. \& MENDONÇA, N.T. de. Estudos sobre a conservação de sementes. XII. Melância. Bragantia, 23:343-50, 1964.

OLIVEIRA, P.J. Influência do armazenamento na germinação e vigor de sementes de feijão-de-corda. Fortaleza, Depto de Fitotecnia. C.C.A., UFC., 1981. 48p. Tese Mestrado.

PARICHA, P.C.; RITH, A.M. \& SAHOO, J.K. Studies on the higroscopic equilibrium and viability of rice stored under various relative humidities. Seed Research, 5(1):1-5, 1977.

PELEGRINI, M.F. Armazenamento de sementes. Informe Agropecuário, Belo Horizonte, 8(91):56-60, jul. 1982.

PIMENTEL, M.L.; AGUIAR, P.A.A. \& SILVA, M.C.L. Conservação de sementes armazenadas nas diversas zonas fisiológicas do Estado de Pernambuco: Pesq. Agropec. Pernambucana, Recife, 2(1):61-72, jun. 1978.

POPINIGIS, F. Fisiologia da semente. Brasília, AGIPLAN, 1977. 289p.

SNEDECOR, G.W. \& COCHRANE, G. Statistical methods, 7th ed. Ames. Iowa State University Press, 1980. 507p.

TOLEDO, F.F. de \& MARCOS FILHO, J. Manual de sementes: Tecnologia de produção. São Paulo, Editora Agronômica CERES, 1977. $224 p$. 